\title{
Restaurant Customer Self-Ordering System: A Solution to Reduce Customer/Guest Waiting Time at the Point of Sale
}

\author{
Edje E. Abel, M.Sc \\ Information Systems Management \\ Department of Mathematics and Computer \\ Science \\ Delta State University, Abraka \\ P.M.B. 01 \\ Delta State, \\ Nigeria.
}

\author{
Ekabua Obeten, Ph.D \\ Software Engineering and Systems \\ Department Mathematics and Computer Science \\ Delta State University, Abraka \\ P.M.B. 01 \\ Delta State, \\ Nigeria.
}

\begin{abstract}
Restaurant Management Information System tends to provide support for restaurant managements in other to serve prospective guests effectively and facilitates inventory control. Presently, the Restaurant Point of Sale System is used by Fast-food Restaurants to take order from guests. In most cases, prospective guests have to wait endlessly on queue before their orders can be taken by Customer Service Providers. This research paper reviews the constraints of the existing system (Restaurant Point of sale system) and proposes a potential System solution called Restaurant Customer Self-ordering System. An architectural research framework Design was also suggested that will aid the design and implementation of the proposed system. The researcher suggested a Clustered based System Architectural Design. Recommendations were also put forward in other to attract Restaurant entrepreneurs to invest in the proposed system. It will assist management to take decisive business decision to cut down capital expenditure on food and beverages that are not highly in demand. Also, how the proposed system could be enhanced in the future was discussed.
\end{abstract}

\section{Keywords}

Restaurant Management Information System (RMS), Restaurant Customer Self-ordering System (RCSS), Restaurant Point of Sale System (RPOSS), Customer Service Provider (CSP), Application Programming Interface(API)

\section{INTRODUCTION}

The pace at which Rrestaurants Mmanagements Information Systems are being deploy in fast-food and beverage industry is fascinating and widely accepted in the world. This has really made a positive impact in the industry over the last decay, as most restaurant entrepreneurs are investing in this technology. This is not only due to the fact that entrepreneurs are rapidly adapting to the technological advancement in the industry, but also relate to the enormous competitive advantage and other benefits that they stand to gain from implementing this emerging technology.

According to Nehiem et al [1], Restaurant Management Information System (RMS) as the crucial technology components that enable a single outlet or enterprise to better serve its customers and aid employees with food and control. In other words, it provide the platform for restaurants to effectively and efficiently attend to customers order at the point of sale, assist employees to carryout transactions accurately and inventory control. Most transactions effected with the aid of RMS limit the tendency of error prone during calculations and other financial transactions.

The growth of a restaurant depends on its management information systems, which manages most transactions such as scheduling personnel to customer service, in other to enhance profitability as well as provide an enabling environment for customers to eat and dine. This can only be possible by the computation of meal and beverage ordering as well as billing inventory control. [2] attest to this claim that RMS tends to "improve food safety, inventory control, service quality, operational efficiency and data visibility".

The computer system that is operated by the employee (customer service provider) in front of you, when you place an order in fast-food restaurant (e g.MC Donald's, KFC, MR Biggs and Sizzlers e $t \mathrm{c}$ ) is a typical example and part of restaurant management information systems. From the researcher's point of view, Restaurant Management Information System can be defined as integrated system components that take orders from customers at the point of sale, send these orders to the kitchen to be process, monitors goods sold, control inventory and generates reports for management decision making.

\section{BASIC COMPONENTS OF RESTAURANT MANAGEMENT INFORMATION SYSTEM}

There are diverse Restaurant Management Information System components which are use in the fast-food industry. These systems comprise of Inventory Menu Managements Control System, Labor scheduling and Time Management System, Reservations and Table Management e t c. The purpose of implementing these system components is to enable restaurants provide quality services, improve service delivery and to be competitive above their rivals. The following comprises of a detailed description of these system components.

\subsection{Inventory and Menu Management System}

The Inventory Control and menu system is designed to allow restaurant managements fast track prices of items purchased from various suppliers over a period of tme. It also provide acurate up-to-date costing of menu. Knowing your "up-todate Menu Costs" saves you big money and prevent costly mistakes in pricing [3]. In order words, the system automatically up-dates manegement menu cost and items 
purchased so as to reduce error prone from pricing. Inventory is classified as food items such as raw meat, rice, beans, vegetable leaves and oil e $t \mathrm{c}$. Items bought from suppliers and their prices are stored on the system. The system also enable management retrieve and up-date prices of items whenever they re-instock.

Menu is referred to categories of cooked food ready for consumption or to be serve to prospective customers. Examples of food menus are, rice and Stew, chips and chicken and chicken burger etc. The system keeps record of these categories of menu and their costing as well as enabling management to up-date menu costing. It also fast track the safety of food menu by alerting management their expiry dates.

\subsection{Labour Scheduling and Time Management System}

Labour scheduling/time management system provides 24/7 labour scheduling, which enable managements in the restaurant industry to "prepare weekly labour schedules for 24-hour periods that keeps track of employee attendance for payroll processing" [3]. This system works in such a way that, it provides access to employee to clockin at the begining of duty and clockout at the end of duty. The total time worked by an employee is computed and forwarded to the payroll system for calcalations. The system also provides variety of features that enable restaurant management to make decisive decisions. These features includes rating of employees performance and ability; "provides reports on employees that were exempted and those that were not during working periods, and allows the desimination of attendace data to an external payroll system" [4].

\subsection{Reservations and Table Management System}

Reservation and table managment system are software applications that allows customers to book for table reservation in a restaurant for the purpose of dining, holding meetings, birthday and wedding receptions e t c. Presently, restaurant managements create an online platform to allow potentail customer access their table reservation management system. Customers can then place a reservation on the number of tables they want, the time and period they would want the table to be available for them to use.

Most table reservation management systems are designed to "provide accurate seating times and record table requests with waitlist capabilities and use the customer management function to maintain guests' information" [5]. Capturing accurate data from guest about their table request and the period they would need the tables put the restaurant management in complete control of the guest dining experience. With this system in place, "restaurant managers \& staff can maintain booking \& reservations proficiently with ease and without any over booking worries" [6].

\section{OBJECTIVE OF THE STUDY}

A comprehensive investigation will be carried out on the existing system used for ordering meals and beverages, in other to explore its challenges and limitations. Also, a propose system solution will be analyse on how it could drastically reduce the challenges and the limitations of the existing system.

\section{RESEARCH FRAMEWORK}

In this section the researcher demonstrates how the research study will be actualize. Firstly, an architectural structure was design which comprise of five stages that will enable the researcher to achieve the research goal. These stages comprise of a detailed insight of the existing system used by restaurants to take customer orders, the challenges faced by the existing system, propose system solution and how it will be use to resolve the challenges posed by the existing system and then ends with recommendation. See diagram below for more insight.

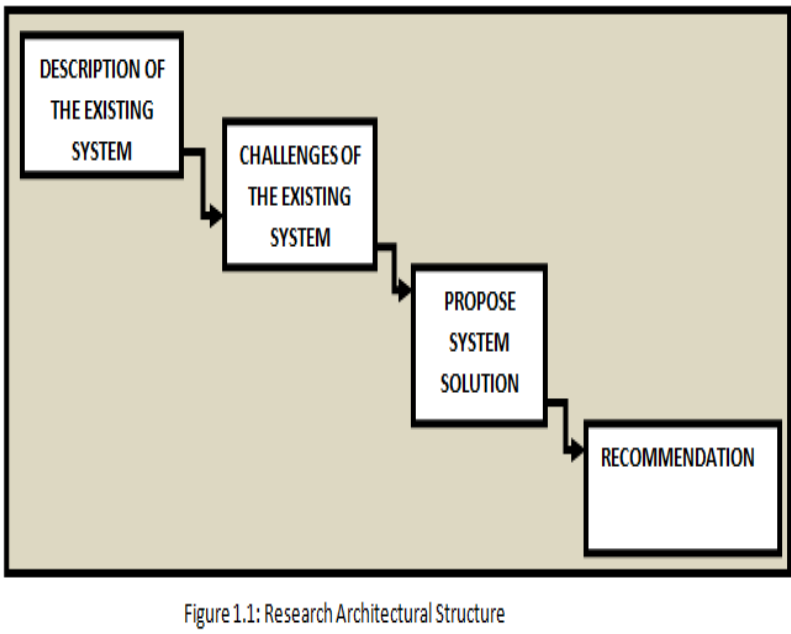

\section{DESCRIPTION OF THE EXISTING SYSTEM}

Over the last decay, Restaurant Industry has tremendously improved on customer services at the point of sale. This is due to the increase of fast-food restaurants outlets, leading to competition among restaurants entrepreneurs. Presently, most fast-food outlets rely heavily on the Restaurant Point-Of-Sale System (RPOS) to take orders from prospective customers/guests. Nyheim et al (2005), defines Restaurant Point-Of-Sale System (RPOS) as either a stand-alone machine or a network of input and output devices used by restaurant employees to accomplish their daily activities such as food and beverages orders, guests-check settlement, credit card transaction processing and charge posting to folios.

In other words, RPOS system enables customer providers (Servers) in restaurants to collect orders from guests, these orders are then processed by the system, and the customer is served after payment is made. The system also provide other functions such as sending food items ordered to the kitchen to be prepared and forwarding sales reports to management on a daily basis e t c. An example of Restaurant Point-Of- Sale System is the machine being used by the customer service provider (Server) in front of you, when you order for food/beverages in fast-food restaurant.

Restaurant Point-Of-Sale system minimizes error prone while taken orders from guests. In order words, it enables orders to be taken accurately from prospective guests. It has a specific field assigned to each food /beverage items. For instance, fried rice may have the field named as "FRDRICE" and that of "Chikenburger" may have the field called "CBurger" e $t \mathrm{c}$. Instead of inputting the food item ordered into the system, the server simply select from list of fields provided by the RPOS. With this system in use, miscommunication and common handwritten errors are eliminated during ordering processes. It 
also aid fast-food restaurant management to determine the performance of their employees. This is achieved by collating how much product is sold by each customer service provider on a daily basis.

\section{CHALLENGES OF THE EXISTING SYSTEM}

In the past five years, there have been tremendous influxes of customers/guests patronizing fast-food restaurants worldwide especially in the developed country. This has posed huge challenges on restaurant management due to the fact that, customer service providers are finding it difficult to cope with the influx of customer orders using the existing Point-of-Sale System. On the other hand, customers/guests are tired of waiting on the queue before being served. According to one of the branch manager of Sizzlers Fast-Food outlets (Based in Nigeria), "Restaurant Management are finding it elusive to minimize the waiting time before a customer is served".

\section{PROPOSE SYSTEM SOLUTION}

This research proposes the design and implementation of Customer Self-Ordering System, as the solution to minimize the waiting time per customer before being served. Customer Self-Ordering System is an emerging system in the hotel and restaurant industry, which as not being implemented or used in any restaurants either in the developed or developing countries. So what then is Ccustomer Self-ordering System? It can be defined as an e-ordering system that allows prospective customers to order for food electronically while in the restaurant. Customers need not to wait endlessly on queue before being served. As the system will limit the time and stress customer passes through waiting on the queue to be serve by customer service providers.

\subsection{Demonstration of how the System will be use by Prospective Customers}

Customer walks into restaurant and sit, in front of him/her is a table consisting of various buttons (depending on the number of chair the table can accommodate). The word "Press Me" is engraved on each button. When the customers press any of these buttons, a touch screen monitor will be display prompting the customer if he would like to eat in the restaurant or take the food home. The customer will respond by selecting the option he wants with his finger. Immediately the customer makes his choice, meal/beverages menu will be displayed prompting the customer to select the type of food he would like to eat. After the customer has selected his choice of meal, the total cost of meal will be displayed on the screen; prompting the customer to select type of payment method (such as credit/debit cards or by cash).

If the customer selects cash payment method, a small tray will eject out from the table. The customer then places the cash equivalent to the total cost of meal on the tray. The system only accepts the money or cash if it is equal or greater than the total cost of meal ordered. If not, it will reject the money prompting the customer to place the right amount of cash on the tray. If the customer insists, the system will automatically shut down in 30 seconds. But if the cash is equal or greater than the total cost of meal ordered, the system will accept the cash, refund balance ( $\mathrm{i}$ e, if the money exceed the total cost) and a receipt will be printed out to the customer.

Immediately the customer collect his receipt, a message will be displayed on the monitor informing the customer the time the meal will be serve. Also, he will be prompted by the system if he would like to edit the order made already, make another fresh order or better still end order. If the customer selects the Edit, the order he made initially will be displayed to allow changes to be done. If he select make a "fresh order" the system will iterate back to the start up menu (as discussed above). But if the customer selects "end order", the system will automatically shut down.

The same procedure applies to other payment methods such as credit/debit cards. In a situation whereby the customer intends to pay for order made via credit/debit card, he/she will be prompted to slot the card and enter pin code. The system will verify the validity of the card number and pin-code; if they are valid the system deducts the said amount from the customer account and issue a receipt. But if the money in the customer account is not enough, the system will display a message "insufficient fund" and automatically shut down in thirty seconds.

\section{SYSTEM ARCHITECTURAL FRAMEWORK DESIGN}

The researcher has proposed the use of clustered based system framework to actualise the development of the proposed system solution discussed in the previous section above. Application software will be implemented to run on the said clustered system. See diagram below for more insight.

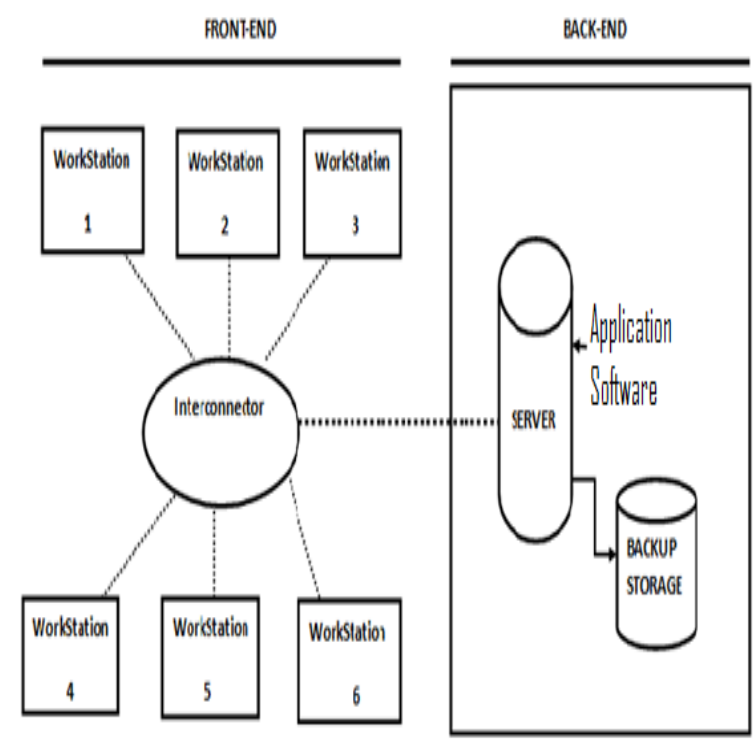

CUSTERED BASED SYSTEM LCHITECTURALFRAMEWOFK

Figure 1.2: Clustered Based Svstem Architectural

The proposed Clustered Based System Architectural framework comprise of front and back end components. The front-end consists of work stations (with an inbuilt Touch screen Technology) mounted on tables in the restaurant to enable prospective customers order for food. These workstations are then connected to an interconnector device that is linked a server at the back-end system components. The back-end system is made up of a dedicated server (it could be more than one the depending on the scale of restaurant in terms of customer patronage) and a backup storage component. The application software will reside on the server. The backup storage component is used to store all order information from prospective customers.

The interface (API) of Application software may be implemented with visual Basic.Net while its database could be implemented with MySql. With the system in place, 
management of fast food restaurant can keep track of total number of customers that patronises their outlet on a daily, monthly and annual basis. The order information obtained may be use to forecast the profit gained in a certain period of time. Also, it can provide vital information about the type of food and beverages that are often sold and those that are not on a regular basis. This information may assist management to take decisive business decision to cut down capital expenditure on food and beverages that are not highly in demand.

\section{RECOMMENDATIONS AND CONCLUSION}

The proposed system solution will go a long way to reduce waiting time at point of sale and minimizes the burden on customer service providers in fast-food restaurants. Fast-food restaurant entrepreneurs should embark on the implementation and adoption of Restaurant Costumer Ordering System in their outlets. As it will enhance the rate of customer ordering, attracts more customers/guest, effectiveness and efficiency of the day-to-day running of business transactions.

The proposed system solution can also be integrated with existing Restaurant Management Information Systems currently used in any fast-food restaurants. Examples of Restaurant Management Information systems include Table Reservation System, Inventory System and Labour Scheduling System e t c.

In conclusion, the propose system solution has the potentials to improve customer ordering at the point of sale however it may pose some challenges during and after its implementation in restaurants. These challenges may include, cost of implementation, integrating it to other existing system in the restaurant may lead to system failure and staff (customer service providers) may not accept the idea of adopting it due to the safety of their jobs e $t \mathrm{c}$.

Future research can be carried out on the proposed system solution. This could be done by implementing a web based Restaurant Customer Self-ordering System whereby, prospective customer/guest can access food menu/beverages and place an order via the internet with the use of mobile phones and PDAs, at anytime irrespective of their geographical location. This will attract a wider range of audience and potential customers/guests.

In the future, we intend to develop software that will run on a portable digital device (e g, palm top), which would enable prospective customers make order while in the restaurant as well as from home. This can be done by creating a hotspot for the restaurant, so that when a customer comes close or in the restaurant it can connect to the software via the hotspot. Customer can as well order meal from the restaurant by using the propose software via internet connectivity. In actual sense we presume that the restaurant most have a website. The propose software will then be integrated into the website.

\section{REFERENCES}

[1] Peter D. Nyheim, Francis M. Mcfadden, and Daniel J. Connelly (2005). Technology Strategies for Hospitality
Industry, Peason Prentice Hall, Upper Saddle River, New Jasey, United State of America.

[2] Ngai E. W. T., Suk F. F., and Lo S. Y. Y. (2008). Development of an RFID-based sushi Managment: The Case of a Conveyor-belt Sushi Restaurant, International Journal of Economics, Volume 112, Page 630-645.

[3] RestaurantPlus (2005). Restaurant Software, Restaurant Systems \& Support, http://restaurantplus.com/Highlights/back-officesoftware.htm (Accessed Date: 30-09-2013).

[4] Genesistems Inc (2011). Foodservice Management Information System V (FMIS V), http://www.genesistems.com/restaurant.htm (Access Date: 30-09-2013).

[5] Hospitality Solutions International (2013). Table Management System; Complete control from the moment guests are greeted, http://dnn.hsisolutions.com/Solutions/Consumer-Solutions/TableManagement-and-Reservation-Solutions.aspx, (Date Accessed: 21-10-2013).

[6] Maitredee360 (2011). Web-Based Hotel Booking Software, www.urlm.com, (Accessed Date: 22-08-2014).

[7] Valeria Minghetti (2003). Building Customer Value in the hospitality Industry: Towards the Definition of a Customer-Centric Information System, Journal of Information and Technology and Tourism, Volume. 6, Page 141-152.

[8] Karl W. Wober (2003). Information Supply in Tourism Management by Marketing Decision Support Systems, Journal of Tourism Management, Volume 24, Page 241255.

[9] Mohammed El Dief (2012). Determinants of Environmental Management in the Red Sea Hotels: Personal and Organisational Values and Contextual Variables, Journal of Hospitality and Tourism Research, Volume 36, Issue Number. 1, Page 115-137.

[10] Dana V. Tesone (2006). Hospitality, Information Systems and E-commerce, John Wiley \& Sons Inc, Hoboken, New Jasey, United State of America.

[11] Kelly Rainer and Casey G. Cegielski (2009), Information Systems Supporting and Transforming Business, $3^{\text {rd }}$ Edition, John Wiley and Sons Inc, Hoboken, New Jasey, United State of America.

[12] Devra Gartenstein (2013). Management Information Systems in Restaurants, http://www.ehow.com/info_8030472_managementinformation-systems-restaurants.html (Date Accessed:2509-2013).

[13] Hotfrog (2013). Restaurant Booking System, Restaurant Table Management, Restaurant Reservation Software, http://www.hotfrog.co.uk/Companies/TableControl/Resta urant-Table-Management-144015 (Date Accessed: 2110-2013) 